\title{
Hybrid Switched Reluctance Motor and Drives Applied on a Hybrid Electric Car
}

\author{
Qianfan Zhang, Xiaofei Liu, Shumei Cui, Shuai Dong and Yifan Yu \\ Harbin Institute of technology
}

China

\section{Introduction}

Electric machine is one of key parts in hybrid electric vehicles which affect dynamical and fuel consumption features and is the kernel to realize all kinds of strategy. Induction motor, PM synchronous motor, brushless DC motor, and switched reluctance motor are all applied in HEV. Traction motors for HEV are different from motors applied in industry. Load changes frequently and widely. Characteristics such as high maximum torque and maximum speed, high ratio of maximum speed to base speed usually larger than 4, high efficiency over whole work area, smaller volume and lighter weight with high power are demanded. Moreover, electric machine is usually installed on the chassis on which the environment is vibrative, dusty and moist. So characteristics of traction motors for HEV should be as follows, high power and torque density, extended speed range, high efficiency over whole working area, shockproof, waterproof, and dustproof.[1] A novel hybrid switched reluctance motor drives are developed. With simple flux adjusting, large torque and high speed are achieved. With a coil stationary in the motor, rotor position is detected and speed is calculated.

The torque-speed characteristic curve and system efficiency map of the electric machinery applied on HEV are important items in power assembly test. The electric machinery will help to start the engine or the vehicle, assist to drive the vehicle, charge the battery and absorb the braking power or sometimes reverse the vehicle. So the electric machines often work in both motor and generator mode, and sometimes run both forward and reversal. It is to say that the working torque-speed area is distributed in 2 or 4 quadrants. The magnetic particle brake and electric eddy current load as in normal electric machinery test bed cannot work because they cannot drag the tested electric machinery. Some electrical dynamometer can do that kind of test. But with the unit of generating to the grid, the system is expensive. A bench is developed to test the motor drives. It is energy saving and no power flows to the grid.

\section{Power train and control strategy of the hybrid electric car}

Fig.1 shows the structure of drive assembly of hybrid electric car. There are 3 electric machineries, G/M, starter and $\mathrm{M}$, in the figure. $\mathrm{G} / \mathrm{M}$ is an integrated started and generator (ISG) which connects with the internal combustion engine (ICE) with belt. The starter is a standby one. The $\mathrm{M}$, which is subject of the paper, is called main motor. It connects with the wheels through the final gear. The batteries are $\mathrm{NiH}$ batteries $(288 \mathrm{~V}, 10 \mathrm{Ah})$. 


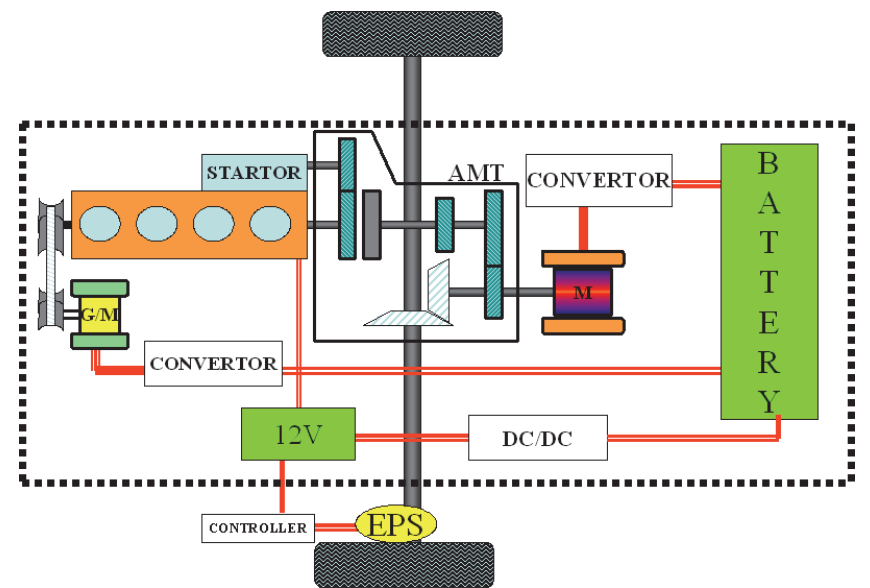

Fig. 1. Power assembly diagram of hybrid electric car

The hybrid electric car has 8 working modes: idle stop, ICE drive, motor drive, serial mode, parallel mode, serial \& parallel mode, ICE drive \& battery charge and regenerative brake. Fig. 2 shows power flowing in 4 modes of them.

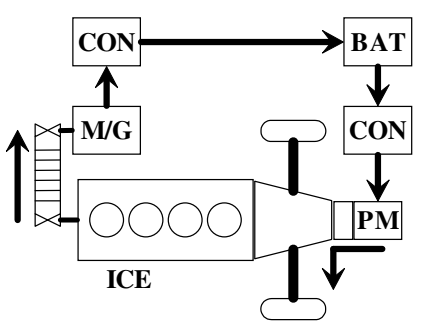

Serial mode

(a)

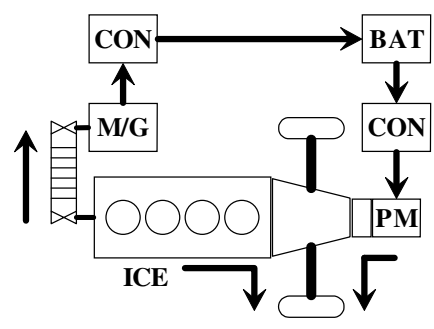

Serial\&Parallel mode

(c)

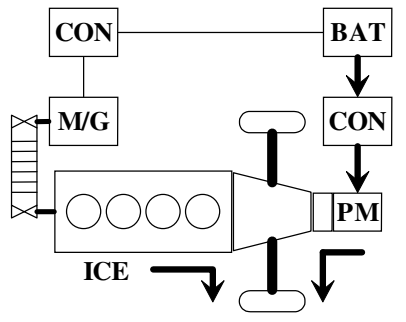

Parallel mode

(b)

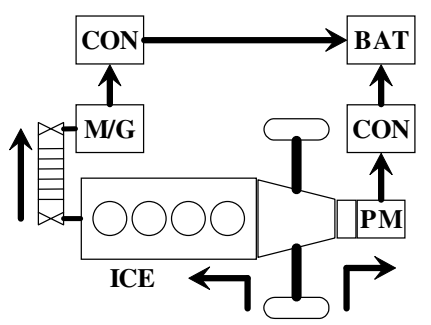

Regenerative brake

(d)

Fig. 2. Working modes and power flow route of hybrid electric car

ICE stops running when it is in idle running state and started in no more than $100 \mathrm{~ms}$ by $M / G$ to work again. The idle stop mode will eliminate fuel consume and emission in idle 
running state. ICE drive mode is the same as the traditional car and will occur in most efficient working area of ICE. The motor drive mode is the same as the battery electric car and will occur in very low speed. In serial mode which is shown in Fig.2 (a), ICE drags M/G to charge the battery, and $\mathrm{M}$ drives the wheel. In parallel mode which is shown in Fig.2 (b), both ICE and M drive the wheel. It will occur when high output is needed. Serial \& parallel mode is shown in Fig2 (c). When the state of charge (SOC) is low, ICE drags M/G to charge the battery and drives the wheels at the same time. In regenerative brake mode shown in Fig.2 (d), M/G and M work in generator mode to charge the battery. These will distinctly decrease the fuel consume

\section{Operating points simulation of the electric machine}

In order to design the speed and torque range of electric the machine, especially the base speed, the simulation based on vehicle drive mode and control strategy is developed on Simulink ADVISOR, an electric vehicle simulation software. Under the ECE-EUDC drive cycle, the working points of electric machinery are simulated. According to it, the base speed of the electric machinery is decided. The electric machinery drives system is designed according to the frequently working points. The main electric machinery is the subject of the paper. The design process of the $M / G$ is the same.

According to the hybrid degree of this hybrid car, the power of $\mathrm{M}$ is $20 \mathrm{~kW}$; the maximum rotation speed is $5000 \mathrm{rpm}$. According to the simulation, the large torque and low base speed electric machinery is fit for the car. The simulation results of two electric machineries with the same power are presented here. One with base speed of 1280rpm is called low base speed electric machinery. The other with base speed of $4000 \mathrm{rpm}$ is called high base speed one.

The basic parameters of the vehicle are shown in the Table 1.

The power of $1.5 \mathrm{l}$ ICE is $43 \mathrm{~kW}$. The transmission is auto transmission. Power of G/M is $8 \mathrm{~kW}$. Table.2 shows the simulation results of ICE drive only, with high base speed electric machinery and with low base speed electric machinery. The simulation condition is the same. With the highest torque, the drive assembly with low base speed electric machinery obtains better dynamic performance. And its fuel consume is lower, because the ICE work in more efficient area. These can be found in simulated ICE working points under 1 ECEEUDC cycle in Fig.3.

\begin{tabular}{c|c|c|c|c|c}
\hline $\begin{array}{c}\text { Mass/ } \\
\mathrm{kg}\end{array}$ & $\begin{array}{c}\text { Coefficient of } \\
\text { rolling } \\
\text { resistance }\end{array}$ & $\begin{array}{c}\text { Coefficient of } \\
\text { aerodynamic } \\
\text { drag } \mathrm{C}_{\mathrm{d}}\end{array}$ & $\begin{array}{c}\text { Vehicle } \\
\text { frontal } \\
\text { area/ } \mathrm{m}^{2}\end{array}$ & $\begin{array}{c}\text { Wheel } \\
\text { radius/m }\end{array}$ & $\begin{array}{c}\text { Transmission } \\
\text { efficiency }\end{array}$ \\
\hline 1655 & 0.00917 & 0.31 & $2.15 \mathrm{P}$ & 0.301 & 0.92 \\
\hline $\begin{array}{c}1^{\text {st }} \text { gear } \\
\text { ratio }\end{array}$ & $2^{\text {nd }}$ gear ratio & $3^{\text {rd }}$ gear ratio & $\begin{array}{c}4^{\text {th }} \text { gear } \\
\text { ratio }\end{array}$ & \multicolumn{2}{|c}{ Final gear ratio } \\
\hline 3.6 & 2.125 & 1.32 & 0.857 & \multicolumn{2}{|c}{3.889} \\
\hline
\end{tabular}

Table 1. Basic parameters of the vehicle 


\begin{tabular}{c|c|c|c|c}
\hline & $\begin{array}{c}\text { Fuel consuming } \\
\text { per 100km/1 }\end{array}$ & $\begin{array}{c}0-96.6 \mathrm{~km} / \mathrm{h} \\
\text { acceleration } \\
\text { rate/s }\end{array}$ & $\begin{array}{c}64.4-96.6 \mathrm{~km} / \mathrm{h} \\
\text { acceleration } \\
\text { rate/s }\end{array}$ & $\begin{array}{c}\text { Grade with } \\
\text { speed of } \\
88.5 \mathrm{~km} / \mathrm{h}\end{array}$ \\
\hline $\begin{array}{c}\text { Only ICE } \\
\text { drive }\end{array}$ & 6.7 & 84 & 53.9 & $3.5 \%$ \\
\hline $\begin{array}{c}\text { With high } \\
\text { base speed } \\
\text { motor }\end{array}$ & 6.1 & 33 & 10.9 & $5.7 \%$ \\
\hline $\begin{array}{c}\text { With low } \\
\text { base speed } \\
\text { motor }\end{array}$ & 5.2 & 21.5 & 9.5 & $6.3 \%$ \\
\hline
\end{tabular}

Table 2. Simulation result

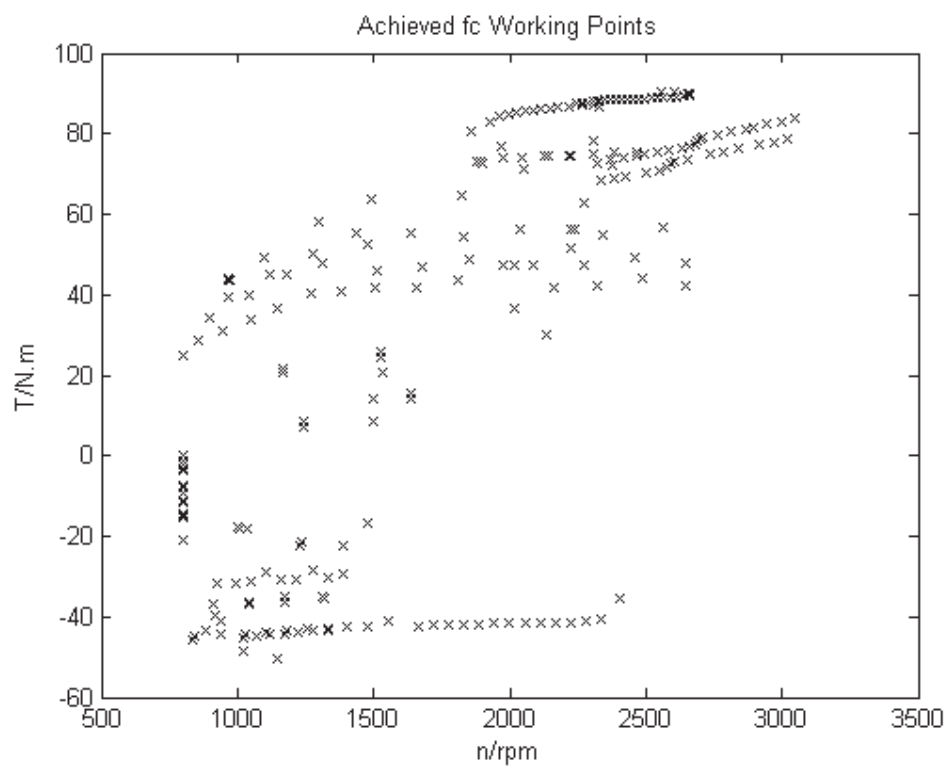

(a) ICE working alone without any motors 


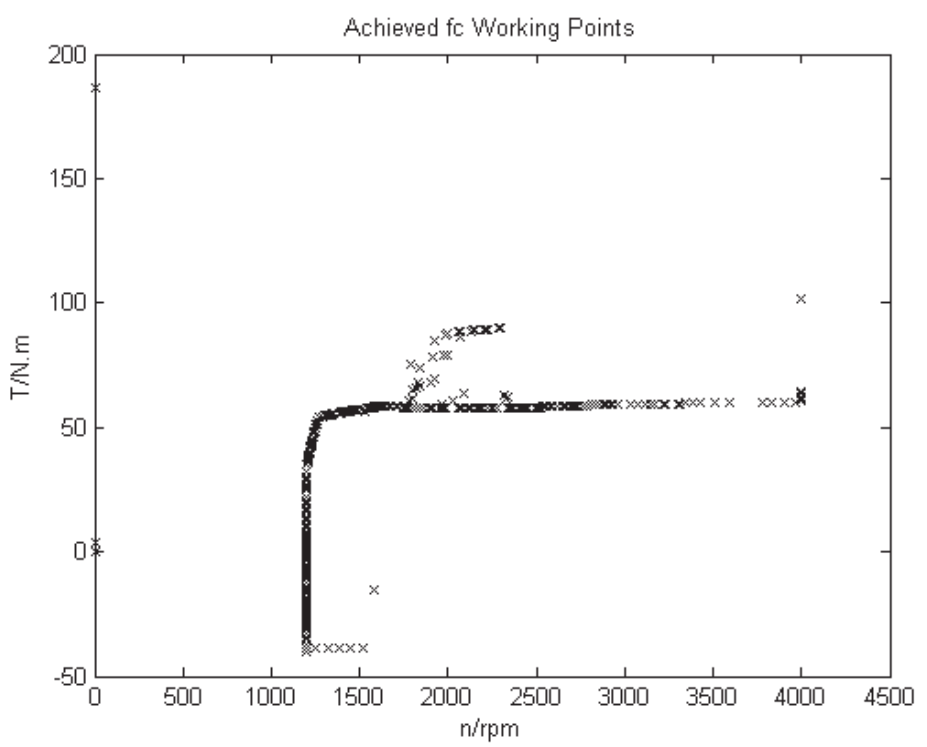

(b) ICE working with high base speed main motor

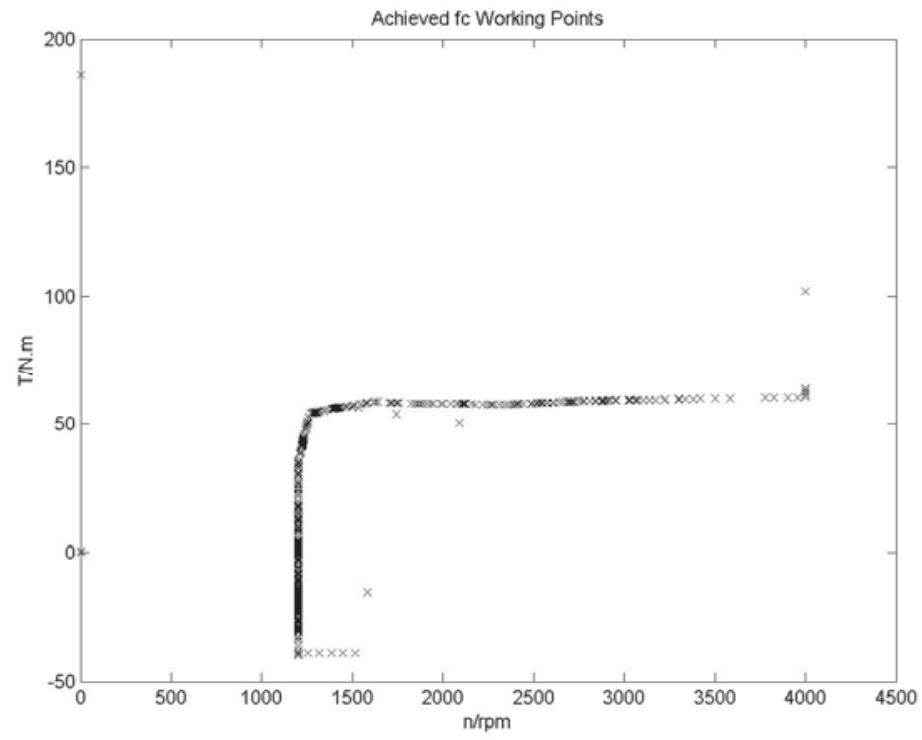

(c) ICE working with low base speed main motor

Fig. 3. Working points of ICE

Base on the simulation analysis and considering other factor, the parameter of the main electric machinery is as the data in table 3. 


\begin{tabular}{c|c|c|c}
\hline Power/kW & Max torque/ N.m & Rate torque/ N.m & Base speed/rpm \\
\hline 20 & 150 & 63 & 1280 \\
\hline
\end{tabular}

Table 3. Parameters of the main electric machinery

During 1 ECE-EUDC cycle, the main electric machinery working points are shown in Fig.4. The drive system design will emphasize on frequently working points.

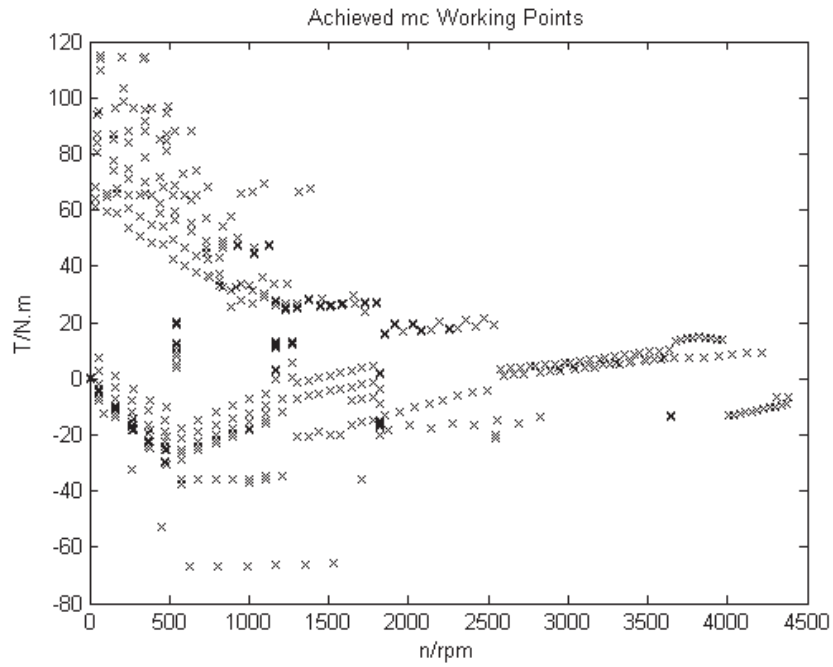

(a) Working points
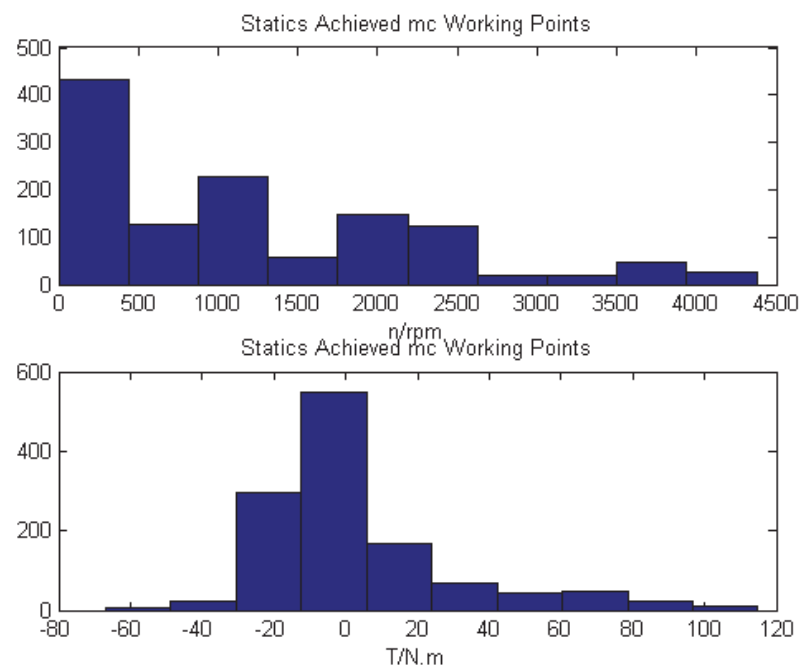

(b) Statistical data

Fig. 4. Working points of low base speed main motor during one ECE-EUDC cycle 


\section{Architecture and principle of the novel electric machine}

According to the analysis above, a hybrid switched reluctance motor with flux adjustment is developed to obtain low base speed torque-speed features of the main motor. Hybrid switched reluctance motor is developed from Hybrid Stepper Motor. In the motor, there are axial excitation coils on both sides of end cover, which is different from HB stepper motor. These coils produce axial flux which is controlled to compensate and adjust PM flux.

A structure figure of a three-phase hybrid switched reluctance motor is shown in Figure 5. The motor consists of: rotor core 1, stator core 2, radial air gap 3, radial three phase excitation coil 4, axial magnetization permanent magnet 5 , axial compensatory excitation coil core 6, axial compensatory excitation coil 7, magnetized end cover 8 , magnetized housing 9, axial air gap 10, and axes 11. 12 indicates the path of flux produced by axial compensatory excitation coil and 13 indicates the path of PM flux. Except for 6, 7 and 10, the structure is same as HB stepper motor. Axial compensatory excitation coil and core are coaxial in line with PM through axial air gap. Controlling the value and direction of currents flowing in axial coil will compensate and adjust axial flux mainly produced by PM. Consequentially, the main flux is adjustable.

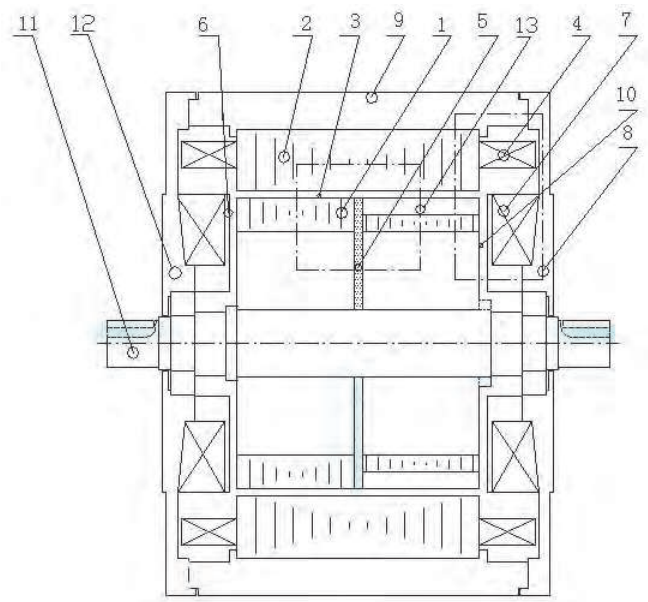

1 - rotor core, 2 - stator core, 3 - radial air gap, 4 - radial three phase excitation coil (armature), 5 magnetization permanent magnet, 6 - axial compensatory excitation coil core, 7 - axial compensatory excitation coil, 8 - magnetized end cover, 9 - magnetized housing, 10 - axial air gap, 11 - axes, 12 - flux path produced by axial compensatory excitation coil, 13 - flux path produced by permanent magnet

Fig. 5. Structure figure of 3-phase axial excited hybrid reluctant motor

Like the three-phase hybrid HB stepper motor, there are six big poles on stator core 2. Radial coils 4 are wound on the pole. On the pole face, are several teeth. Rotor core 1 consists of two parts, core 1-1 and core 1-2. Permanent magnet 5 is laid between 1-1 and 1-2, it is magnetized in the direction of the axe. On the rotor core 1, are several teeth. Pitch is same as that of the stator teeth. Relative departure of centerline of teeth on 1-1 from that on 1-2 is half pitch. To the two neighborhood stator poles, relative departure of centerline of stator tooth from rotor tooth is different by one-third pitch. It means that, to one stator pole, the centerline of stator tooth aligns with that of the rotor tooth, and then on the neighborhood 
stator pole, the centerline of stator tooth departs from that of rotor tooth by one-third pitch. Stator core 2 and rotor core 1 is connected by bearing, and the gap between 1 and 2 is the air gap 3.

The path of flux produced by PM is shown in Figure 5 by 13. Flux flows through rotor core 1-1, radial air gap 3, stator core 2, radial air gap 3 and rotor core 1-2. Path of flux produced by axial coils is shown in Figure 5 by 12. Flux flows through core 6, axial air gap 10, rotor core 1, radial air gap 3, stator core 2, magnetized housing 9 and magnetized end cover 8 . Flux produced by three-phase coil 4 flows through stator pole body, radial air gap 3, rotor core 1, radial air gap 3, neighborhood stator pole body and yoke. MMF produced by 5, 7 and 4 constitutes hybrid space flux path. Commutating currents in three-phase coils 4 produces rotating space magnetic field and then motor will rotate. Controlling currents in axial coils and radial coils will adjust main flux in air gap.

\section{Rotor position sensing}

Consider the axial coil on the side of 1-1 in Fig.5. When current flows in the coil, main flux linking the coil is produced by coil itself and radial excitation coil on the stator poles. Because of the drop of MMF on the sheet gap of rotor core, the effect of flux by PM is weak. This effect is ignored in analysis. The equivalent circuit of flux path on side of 1-1 is shown in Figure 6.

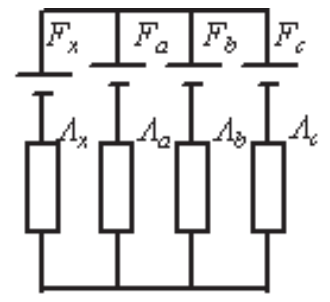

Fig. 6. Equivalent circuit of flux path on side of 1-1

Consider that MMF $F_{x}, F_{a}, F_{b}$ and $F_{c}$ apply respectively, then flux flows through $\Lambda_{x}$ is $\Phi_{0}, \Phi_{1}$, $\Phi_{2}, \Phi_{3}$ respectively, and

$$
\begin{aligned}
& \Phi_{0}=\frac{F_{x}}{\frac{1}{\Lambda_{x}}+\frac{1}{\Lambda_{a}+\Lambda_{b}+\Lambda_{c}}} \\
& \Phi_{1}=\frac{\frac{F_{a}}{\frac{1}{\Lambda_{a}}+\frac{1}{\Lambda_{x}+\Lambda_{b}+\Lambda_{c}}} \cdot \frac{\Lambda_{x}}{\Lambda_{x}+\Lambda_{b}+\Lambda_{c}}}{\Phi_{2}=} \frac{\frac{F_{b}}{\frac{1}{\Lambda_{b}}+\frac{1}{\Lambda_{x}+\Lambda_{a}+\Lambda_{c}}} \cdot \frac{\Lambda_{x}}{\Lambda_{x}+\Lambda_{a}+\Lambda_{c}}}{\Phi_{3}=} \frac{\Lambda_{x}}{\frac{1}{\Lambda_{c}}+\frac{1}{\Lambda_{x}+\Lambda_{b}+\Lambda_{a}}} \cdot \frac{\Lambda_{b}+\Lambda_{a}}{\Lambda_{x}+n}
\end{aligned}
$$


It is DC current in axial coils, and three-phase AC current in radial coils. Only consider basic-frequency component of AC current, then

$$
\begin{aligned}
& F_{x}=N I_{x} \\
& F_{a}=N I \sin \omega t \\
& F_{b}=N I \sin \left(\omega t-\frac{2}{3} \pi\right) \\
& F_{c}=N I \sin \left(\omega t-\frac{4}{3} \pi\right)
\end{aligned}
$$

where

I maximum value of basic-frequency component current in radial excitation coil. Ignore saturate effect, flux $\Phi$ linking axial coil is

$$
\Phi=\Phi_{0}+\Phi_{1}+\Phi_{2}+\Phi_{3}
$$

When (3) is substituted by (1) and (2), we obtain

$$
\begin{aligned}
& \Phi=\left(\Lambda_{x}-\frac{\Lambda_{x}^{2}}{\Lambda_{x}+3 \Lambda_{0}}\right) \cdot N I_{x}+\frac{3 \Lambda_{3} N I_{x} \Lambda_{x}^{2}}{\left(\Lambda_{x}+3 \Lambda_{0}\right)^{2}} \cos (3 \cdot \omega \cdot t)+ \\
& \frac{3}{2} \frac{N \Lambda_{x} \Lambda_{2} I}{\left(\Lambda_{x}+3 \Lambda_{0}\right)} \sin (3 \cdot \omega \cdot t)-\frac{9 \Lambda_{3} \Lambda_{2} \Lambda_{x} N I}{4\left(\Lambda_{x}+3 \Lambda_{0}\right)^{2}} \sin (6 \cdot \omega \cdot t)
\end{aligned}
$$

From (4), we see that when 3-phase balance AC current flows in radial coils and DC current flows in axial coils, flux linking the axial coil consists of constant component and frequency components of value multiplied by 3 .

EMF $E$ in axial coil is

$$
E=-N \frac{d}{d t} \Phi
$$

Substitutes (5) by (4), we obtain

$$
E=\frac{9}{2} \frac{N \Lambda_{x} \omega}{\left(\Lambda_{x}+3 \Lambda_{0}\right)^{2}}\left(\begin{array}{l}
2 \Lambda_{3} \Lambda_{x} I_{x} \sin (3 \cdot \omega \cdot t)- \\
N I \Lambda_{2}\left(\Lambda_{x}+3 \Lambda_{0}\right) \cos (3 \cdot \omega \cdot t)+ \\
3 \Lambda_{3} \Lambda_{2} N I \cos (6 \cdot \omega \cdot t)
\end{array}\right)
$$

Frequency component of EMF in axial coil is third order and the order multiplied by 3. It means that the axial coil can be the position sensor of rotor by detecting zero value of the signal.

\section{Motor drives}

\subsection{Flux adjustment control method}

Vector control is executed to achieve flux weakening control in permanent magnet synchronous motor. The current in the armature is resolved into direct axis current and 
quadrature axis current. Controlling the direct axis current to produce anti-direction flux with main flux by magnetic pole, the flux weaken control is achieved. To the axial excited hybrid reluctance motor, flux-weakening control can be achieved by simply controlling the current magnitude in the axial exciting coil. The control is simplified. The following is the resolve of the torque and maximum speed of the motor. They theoretically show how the flux weakening and strengthening control of the motor is achieved.

The phase voltage equation of the 3 -phase motor is

$$
\begin{aligned}
{\left[\begin{array}{l}
u_{A} \\
u_{B} \\
u_{C}
\end{array}\right]=} & R\left[\begin{array}{l}
i_{A} \\
i_{B} \\
i_{C}
\end{array}\right]+\left[\begin{array}{ccc}
L & M & M \\
M & L & M \\
M & M & L
\end{array}\right] \cdot \frac{d}{d t}\left[\begin{array}{l}
i_{A} \\
i_{B} \\
i_{C}
\end{array}\right] \\
& +\frac{d}{d t}\left[\begin{array}{l}
\psi_{A m}+\psi_{A z} \\
\psi_{B m}+\psi_{B z} \\
\psi_{C m}+\psi_{C z}
\end{array}\right]
\end{aligned}
$$

Where $u_{A}, u_{B}, u_{C} \quad$ voltage of $\mathrm{A}, \mathrm{B}, \mathrm{C}$ phase,

$i_{A}, i_{B}, i_{C} \quad$ current of $\mathrm{A}, \mathrm{B}, \mathrm{C}$ phase,

$R \quad$ resistance of the coil,

$L \quad$ self-inductance of the coil,

$M \quad$ mutual inductance of the coil,

$\psi_{A m}, \psi_{B m}, \psi_{C m}$ magnet flux in A, B, C phase coils induced by permanent magnet,

$\psi_{A z}, \psi_{B z}, \psi_{C z}$ magnet flux in A, B, C phase coils induced by axial coil current.

Ignoring effect of the coil resistance, one phase voltage equation is

$$
u=(L-M) \frac{\mathrm{d} i}{\mathrm{~d} t}+\frac{\mathrm{d}}{\mathrm{d} t}\left(\psi_{m}+\psi_{z}\right)
$$

The vector equation is

$$
\dot{U}=j \omega(L-M) \dot{I}+j \omega\left(\dot{\Psi}_{m}+\dot{\Psi}_{z}\right)
$$

Let the current and voltage vector in the same phase angle, we get

$$
U=\omega \sqrt{(L-M)^{2} I^{2}+\left(\Psi_{m}+\Psi_{m}\right)^{2}}
$$

In the equation $, U=|\dot{U}|, I=|\dot{I}|, \Psi_{m}=\left|\dot{\Psi}_{m}\right|, \Psi_{z}=\left|\dot{\Psi}_{z}\right|$.

From (10),

$$
I=\frac{1}{L-M} \sqrt{\frac{U^{2}}{\omega^{2}}-\left(\Psi_{m}+\Psi_{z}\right)^{2}}
$$

When the voltage across the phase coil is the maximum value which power supply can outputs, the maximum speed of the motor is 


$$
n=\frac{30}{\pi \cdot Z_{r}} \frac{U}{\Psi_{m}+\Psi_{z}}
$$

The magnet flux induced by axial exciting coil current is

$$
\Psi_{z}=L_{z s} I_{z}
$$

where $L_{z s}$ mutual inductance between armature and axial exciting coils,

$I_{Z} \quad$ current flowing in the axial exciting coils.

From (12) and (13), we get

$$
n=\frac{30}{\pi \cdot Z_{r}} \frac{U}{\Psi_{m}+L_{z s} I_{z}}
$$

From (14), we can find that the maximum speed of the motor will increase if the $I_{z}$ is negative. It means that when the magnet flux in the phase coil induced by the axial coil current is not in the same direction with that induced by the permanent magnet, the maximum speed of the motor increases. The flux weakening control is achieved. When the 3 phase coil currents are powered simultaneously, the electromagnetic torque is

$$
T_{e m}=\frac{3}{2} Z_{r}\left(\Psi_{m}+\Psi_{z}\right) I+\frac{3}{4} L_{2} I^{2}
$$

From (11) and (15), we get

$$
\begin{aligned}
T_{e m}= & \frac{3}{2} \frac{Z_{r}\left(\Psi_{m}+L_{z s} I_{z}\right)}{L-M} \sqrt{\frac{U^{2}}{\omega^{2}}-\left(\Psi_{m}+L_{z s} I_{z}\right)^{2}}+ \\
& \frac{3}{4} \frac{Z_{r} L_{2}}{(L-M)^{2}}\left(\frac{U^{2}}{\omega^{2}}-\left(\Psi_{m}+L_{z s} I_{z}\right)^{2}\right)
\end{aligned}
$$

where, $Z_{r} \quad$ number of teeth on rotor;

$\Psi_{m} \quad$ flux linkage produced by permanent magnet;

U voltage on armature;

$\Omega \quad$ rotation speed of the rotor;

$L_{2} \quad$ increment inductance.

The simulation result of torque-rotation speed curves under different axial coil current is shown in Figure 7. In the figure, the bigger the positive axial coil current is, the larger the maximum torque is. The bigger the negative axial coil current is, the higher the working speed with torque is. The electromagnetic torque is not printed in the figure. It is determined by the given maximum current of the armature. We can see that large torque during low speed and acceptable torque during high speed are achieved only by controlling the axial coil current (magnitude and direction). 


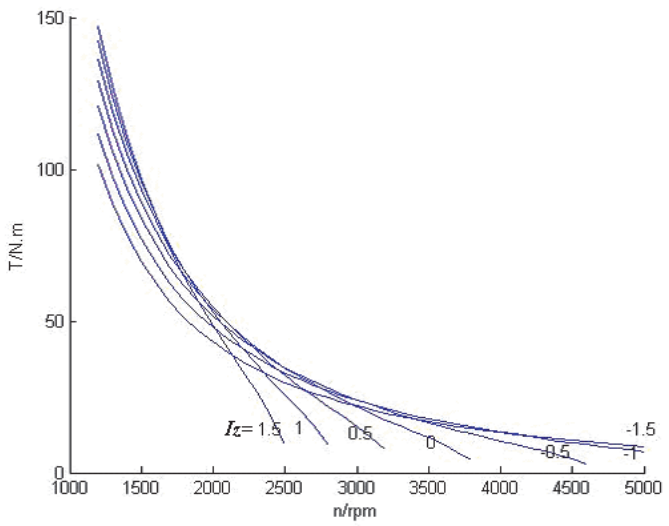

Fig. 7. Torque-rotation speed curve under different axial coil current $I_{z}$

In the simulation, the motor parameters are as shown in the table 4.

\begin{tabular}{c|c|c|c|c|c|c}
\hline$\Lambda_{m} / \mathrm{H}$ & $\Lambda_{z} / \mathrm{H}$ & $\Lambda_{0} / \mathrm{H}$ & $\Lambda_{1} / \mathrm{H}$ & $\mathrm{N}$ & $I_{m} / \mathrm{A}$ & $I_{z} / \mathrm{A}$ \\
\hline $3.654 \times 10-6$ & $7.792 \times 10^{-6}$ & $1.4625 \times 10^{-5}$ & $1.2922 \times 10^{-5}$ & 16 & 200 & $43.75 \times I_{z 0}$ \\
\hline $\mathrm{D} / \mathrm{mm}$ & $1 / \mathrm{mm}$ & $Z_{r}$ & $N_{z}$ & & & \\
\hline 250 & 130 & 16 & 700 & & & \\
\hline
\end{tabular}

Table 4. Parameters of the type motor

In the table, $\Lambda_{m}$ equivalent permeance of the permanent magnet,

$\Lambda_{z}$ equivalent permeance of the axial exiting coils,

$\Lambda_{0}$ permanent value of main air gap permeance,

$\Lambda_{1}$ fundamental value of main air gap permeance

$D$ Diameter of the motor,

$l$ length of the motor,

$N_{Z}$ turns of the axial exciting coils,

$I_{Z 0}$ axial coil current,

\subsection{Principle of hybrid switched reluctance motor drives}

As a main motor in hybrid drive train, torque control is needed in the motor drives. Motor executes the positive torque command in motoring mode and negative torque in regenerative braking and generating mode. When the rotor speed is high, the flux weakening control is needed with limited battery voltage across DC bus. We can control the electromagnetic torque according to equation (16) in the hybrid switched reluctance motor drives.

In order to control the electromagnetic torque according to equation (16), two conditions are needed, which is

1. Vector EMF and current in each armature are in the same angle phase;

2. Current in three phases are powered simultaneously at every time. 
We control three phase armature current as shown in Fig.8. The signal in the axial coils can be modulated into sinusoidal signal with frequency three times of that of the armature EMF. The zero detect pulse of this signal is applied to control the armature current as shown in Fig.8. Two conditions above are satisfied.

Motor drive is developed. The torque control motor drive block diagram of it is shown in Fig.9. Sensor processing section processes the axial coil signal and works as a rotor position and speed sensor. Only controlling the magnitude and direction of the current in the axial exiting coils, the flux strengthening ( giving positive current to the axial exciting coils) and flux weakening (giving negative current to the axial exciting coils) control are realized. When large torque is needed, as starting the vehicle immediately, flux strengthening control is executed. Flux weaken control is executed when charging the battery in high speed. The armature current and EMF keep in the same angle phase.

Simple armature current commuting and axial coil flux adjusting control are developed to achieve large torque and high speed. The control block diagram is shown in figure 9 .

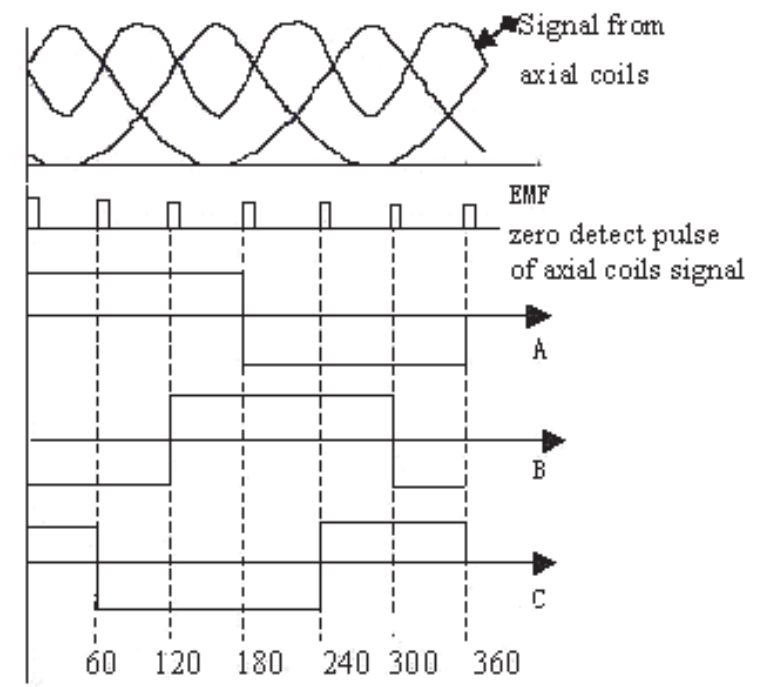

Fig. 8. Diagram of the current control

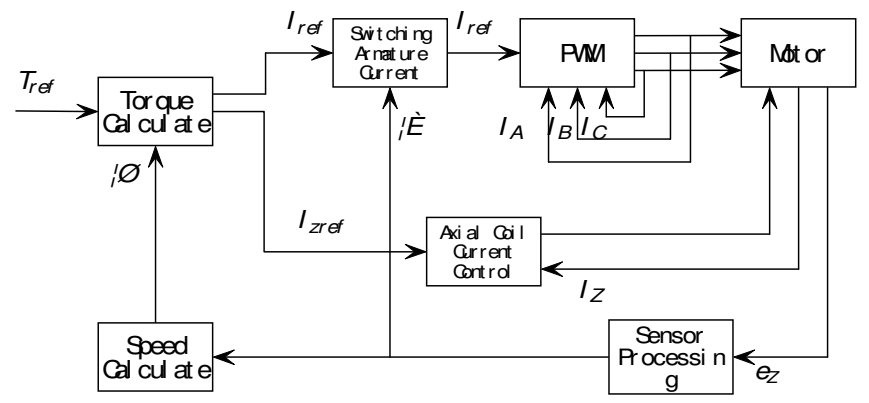

Fig. 9. Block diagram of motor drive control 


\section{Experiment validation}

\subsection{Experiment setup}

The block diagram is shown in the figure 10 to test motor drives in the lab. An electric machine is controlled to simulate load. AC grid, instead of battery, powers motor drives in the lab. The bus voltage value of tested motor drive is $288 \mathrm{~V}$ as in so many EV and HEV. So the voltage of load converter is AC220V. The tested converter and load converter are common DC bus. When tested electric machinery works as a motor, the load electric machinery works as a generator which generates electric power to drive the tested machinery through DC bus, whereas, the tested electric machinery generates power to drive the load machinery. Power flows on the DC bus between the tested and load sides. The power consume is the loss of both the tested system and the load system.

The output power, torque and rotation speed of the tested electric machinery are measured by torque speed sensor. The electric power, AC voltages and currents, and DC voltage and current are measured by the digital power meter.

The speed and torque reference to both the tested and load converter are produced by the computer. All of measured data are acquired by the computer, too. The tested curves are outputted by the post procedure very quickly.

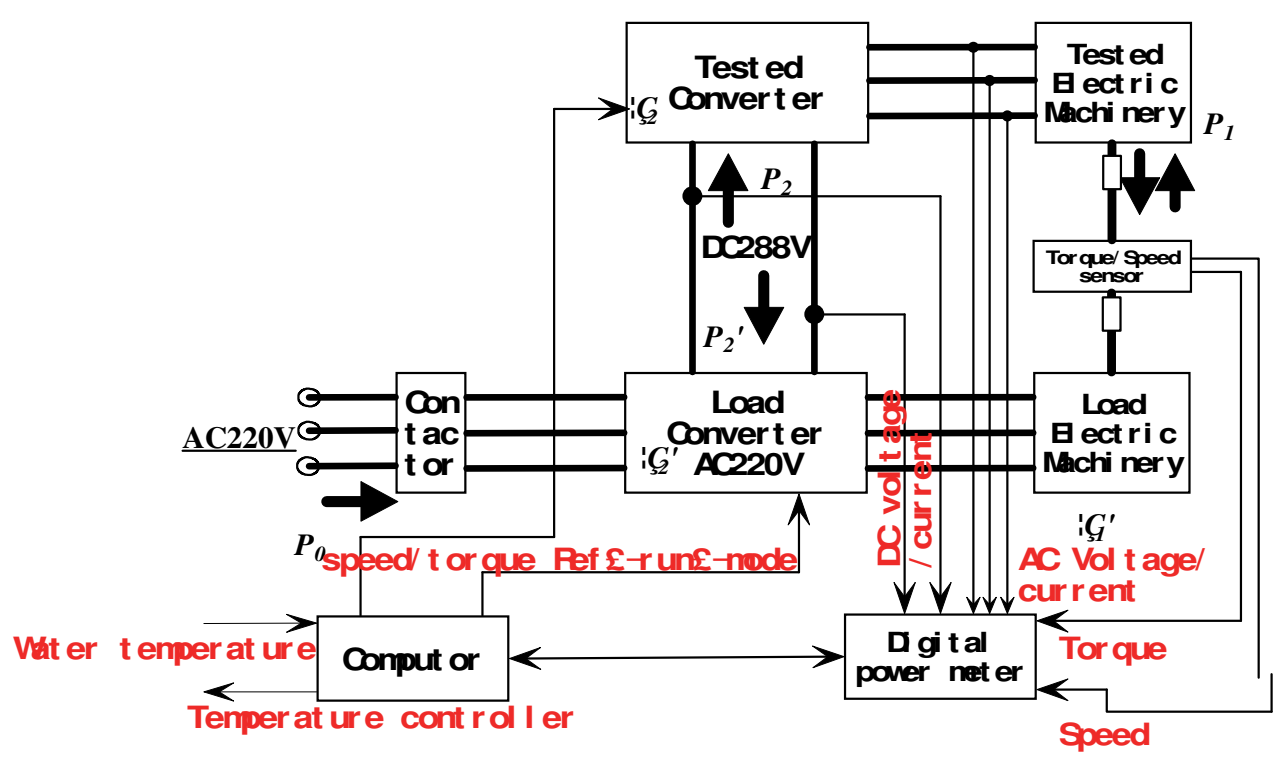

Fig. 10. Block diagram of the test system 


\subsection{Results}

Fig.11, Fig.12 and Fig.13 are the measured wave form of armature EMF (upper one) and axial coil EMF when rotor speeds are $300 \mathrm{rpm}, 1200 \mathrm{rpm}$ and $2400 \mathrm{rpm}$. It is seen that there are 6 zero points in the axial coil EMF signal corresponding in 1 cycle of armature EMF signal which can be the commuted signals to drive motor.

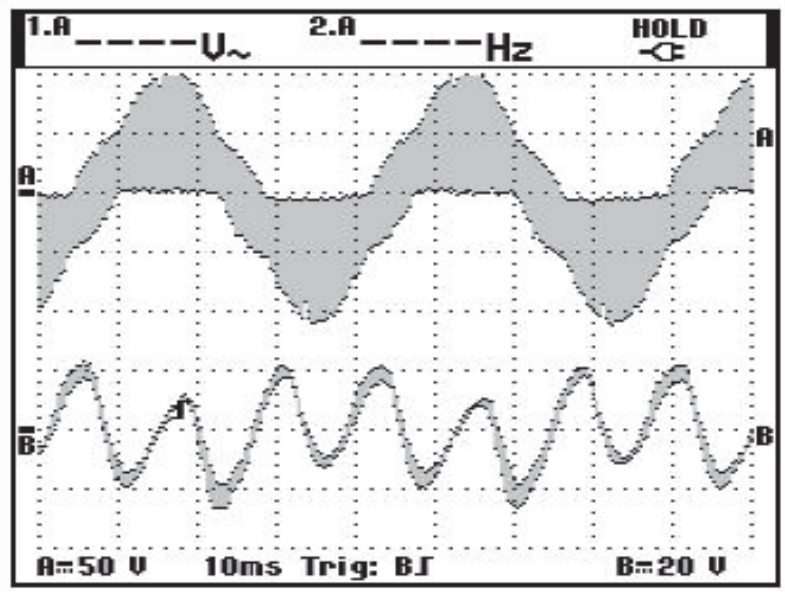

(B: Axial coil EMF, A: Armature EMF)

Fig. 11. Measured wave form of axial coil emf and armature emf when 300rpm

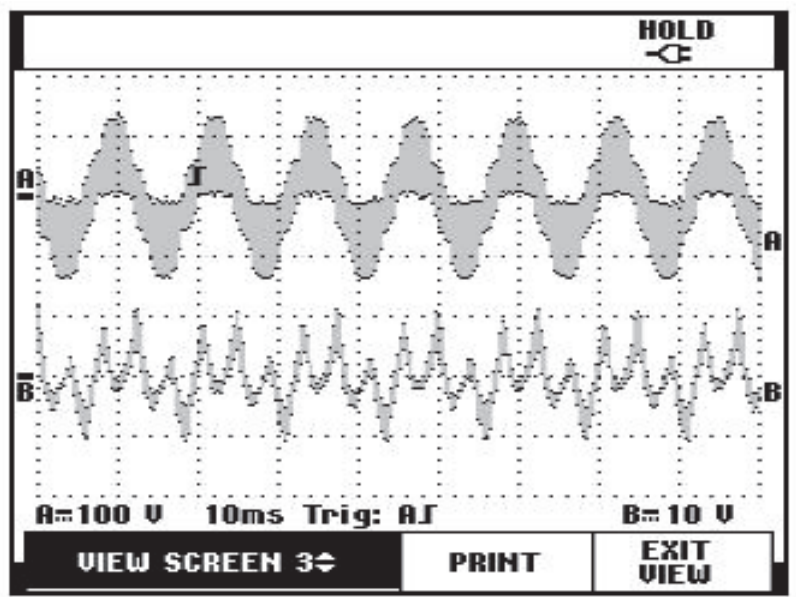

(B: Axial coil EMF, A: Armature EMF)

Fig. 12. Measured wave form of axial coil emf and armature emf when 1200rpm 


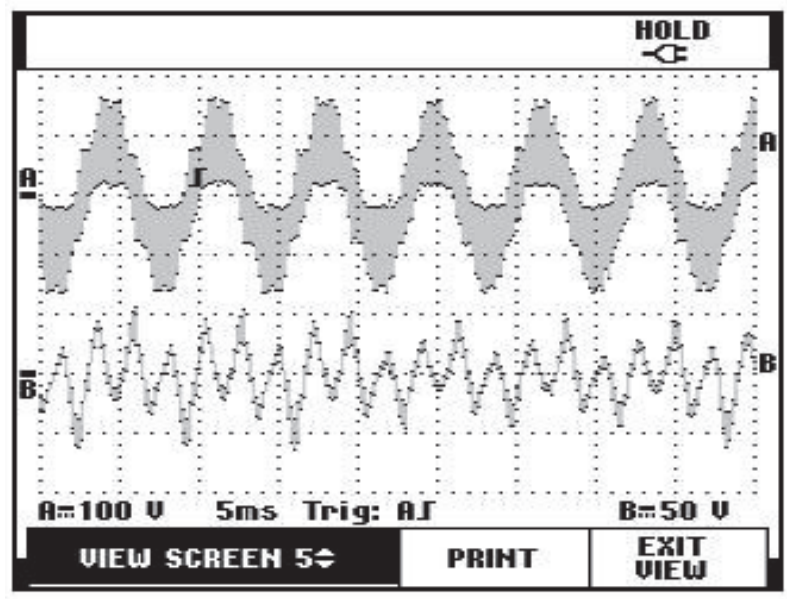

(B: Axial coil EMF, A: Armature EMF)

Fig. 13. Measured wave form of armature EMF and axial coil EMF when 2400rpm

Fig.14 is torque-speed characteristic and efficiency map of the motor drives. Large torque and high speed are obtained by flux adjusting control.

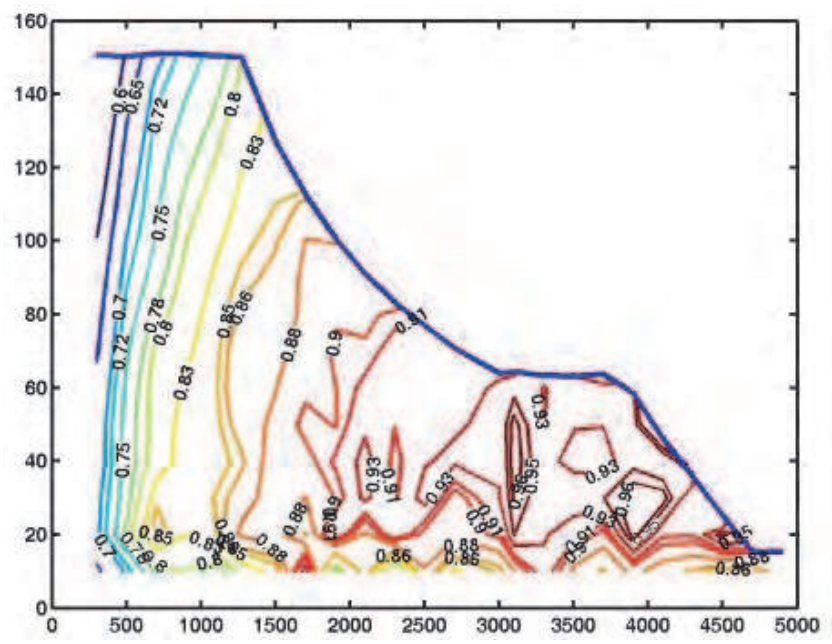

Fig. 14. Efficiency map of the motor drives 


\section{Conclusion}

Demands of motor drive for a Mid-size hybrid electric car are analyzed by simulation. A novel hybrid switched reluctance motor drive is developed which is suitable for applying in electric vehicles. Frequency of EMF in axial coil is three times of that of terminal voltage over one phase of radial coil, and is three times of that of EMF in radial coil. It means that the axial coil can be the position sensor of rotor. Simple flux adjusting control is developed to achieve large torque and high speed. An energy saving test bed is developed. With applying the common DC bus technique, 4-quandrant electric machinery drive characteristic testing is done simply without regenerative power to power grid.

\section{Acknowledgment}

This research is supported by Natural Scientific Research Innovation in Harbin Institute of Technology (HIT. NSRIF. 2009042) and Scientific Research Foundation for Returned Scholars by Harbin Science and Technology Bureau (RC2009LX007004).

\section{References}

[1] Z. Q. Zhu, David Howe. Electrical Machines and Drives for Electric, Hybrid, and Fuel Cell Vehicles. Proceedings of the IEEE, 2007, 95(4):746-765.

[2] Avoki M. Omekanda. A New Technique for Multidimensional Performance Optimization of Switched Reluctance Motors for Vehicle Propulsion. IEEE Transactions on Industry Applications. 2003, 39(3): 672-676

[3] Teven E. Schulz, Khwaja M. Rahman. High-Performance Digital PI Current Regulator for EV Switched Reluctance Motor Drives. IEEE Transactions on Industryl Applications. 2003,39(4): 1118- 1126

[4] Wei Cai, Pragasen Pillay, Zhangjun Tang. Low-Vibration Design of Switched Reluctance Motors for Automotive Applications Using Modal Analysis. IEEE Transactions on Industryl Applications. 2003, 39(4): 971 977

[5] Cheng Shukang, Zheng Ping, Cui Shumei et al. Fundamental Research on Hybridmagnetic-circuit multi-couple Electric Machine, Proceedings of the CSEE, vol.20, no. 4, pp.50-58, 2000.

[6] Zheng Ping, Cheng Shukang. Mechanism of Hybrid- Magnetic-circuit multi-couple Motor. Journal of Harbin Institute of Technology, 2000, E-3(3), pp.66-69.

[7] Zheng Ping, Liu Yong, Wang Tiecheng et al. Theoretical and Experimental Research on Hybrid-magnetic-circuit Multi-couple Motor. Seattle, USA: 39th IAS Annual Meeting, 2004.

[8] Zhang Qianfan, Cheng Shukang, Song Liwei et al. Axial Excited Hybrid Reluctant Motor Applied in Electric Vehicles and Research of its Axial Coil Signal. Magnetics, IEEE Transactions, 2005, 41(1), pp.518-521.

[9] Pei Yulong, Zhang Qianfan, Cheng Shukang. Axial and Radial Air Gap Hybrid Magnet Circuit Multi-coupling Motor and Resolution of Motor Electromagnetic Torque. Power system technology, 2005, supplement.

[10] Zhang, Qian-Fan; Pei, Yu-Long; Cheng, Shu-Kang. Position sensor principle and axial exciting coil EMF of axial and racial air gap hybrid magnet circuit multi-coupling 
motor. Proceedings of the Chinese Society of Electrical Engineering, v 25, n 22, Nov 16, 2005, p 136-141

[11] Zhang Qianfan, Chai Feng, Cheng Shukang, C.C. Chan. Hybrid Switched Reluctance Integrated Starter and Generator. Vehicle Power and Propulsion Conference VPP 2006. September 6-8, 2006. Windsor, UK. 


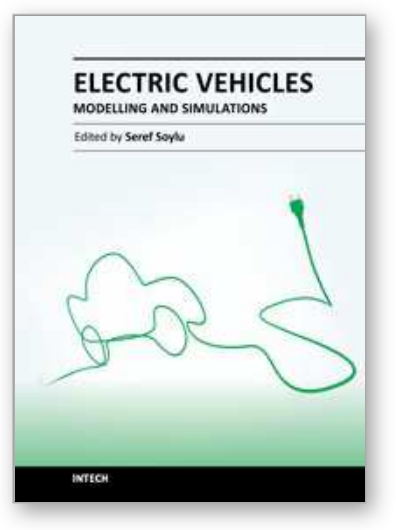

\author{
Electric Vehicles - Modelling and Simulations \\ Edited by Dr. Seref Soylu
}

ISBN 978-953-307-477-1

Hard cover, 466 pages

Publisher InTech

Published online 12, September, 2011

Published in print edition September, 2011

In this book, modeling and simulation of electric vehicles and their components have been emphasized chapter by chapter with valuable contribution of many researchers who work on both technical and regulatory sides of the field. Mathematical models for electrical vehicles and their components were introduced and merged together to make this book a guide for industry, academia and policy makers.

\title{
How to reference
}

In order to correctly reference this scholarly work, feel free to copy and paste the following:

Qianfan Zhang, Xiaofei Liu, Shumei Cui, Shuai Dong and Yifan Yu (2011). Hybrid Switched Reluctance Motor and Drives Applied on a Hybrid Electric Car, Electric Vehicles - Modelling and Simulations, Dr. Seref Soylu (Ed.), ISBN: 978-953-307-477-1, InTech, Available from: http://www.intechopen.com/books/electric-vehiclesmodelling-and-simulations/hybrid-switched-reluctance-motor-and-drives-applied-on-a-hybrid-electric-car

\section{INTECH}

open science | open minds

\section{InTech Europe}

University Campus STeP Ri

Slavka Krautzeka 83/A

51000 Rijeka, Croatia

Phone: +385 (51) 770447

Fax: +385 (51) 686166

www.intechopen.com

\section{InTech China}

Unit 405, Office Block, Hotel Equatorial Shanghai

No.65, Yan An Road (West), Shanghai, 200040, China

中国上海市延安西路65号上海国际贵都大饭店办公楼 405 单元

Phone: +86-21-62489820

Fax: +86-21-62489821 
(C) 2011 The Author(s). Licensee IntechOpen. This chapter is distributed under the terms of the Creative Commons Attribution-NonCommercialShareAlike-3.0 License, which permits use, distribution and reproduction for non-commercial purposes, provided the original is properly cited and derivative works building on this content are distributed under the same license. 